\title{
Determining the Impact of Industrial Wine Yeast Strains on Organic Acid Production Under White and Red Wine-like Fermentation Conditions
}

\author{
B.S. Chidi, D. Rossouw, A.S. Buica, F.F. Bauer* \\ Institute for Wine Biotechnology, Department of Oenology and Viticulture, Private Bag X1, Stellenbosch University, \\ Stellenbosch 7600, South Africa
}

Submittedfor publication: March 2015

Accepted for publication: July 2015

Key words: Fermentation, wine yeast, succinic acid, acetic acid, pyruvic acid

\begin{abstract}
Organic acids are a major contributor to wine flavour and aroma. In the past, the scientific focus has mostly been on organic acids derived from grapes or on the transformation of malic acid to lactic acid by lactic acid bacteria, since these acids contribute significantly to the final total acidity of wine. However, the organic acid concentration and composition also change significantly during alcoholic fermentation, yet only limited information regarding the impact of different yeast strains on these changes has been published. Here we report on changes in organic acid (malic, tartaric, citric, succinic, acetic and pyruvic) composition during fermentation by five widely used industrial wine yeast strains in a synthetic grape must (MS300) reflecting two very different, but both wine-like, fermentation conditions. Samples were obtained from three physiological stages during fermentation, namely the exponential growth phase (day 2), early stationary phase (day 5) and late stationary phase (day 14). These different stages were selected to provide more information on acid evolution throughout fermentation, as well as on the impact of nutritional and environmental conditions during aerobic and anaerobic fermentation. Among other observations, some strains (such as VIN13 and 285) were shown to be generally higher producers of most acids in white and/ or red wine fermentation settings, while other strains (such as DV10) were generally lower acid producers. The data clearly demonstrate that different strains have different acid consumption and production patterns, and this presents a first step towards enabling winemakers to appropriately select strains for acid management during fermentation.
\end{abstract}

\section{INTRODUCTION}

Winemakers are faced with many challenges to adjust products according to consumer demands. Many studies have been dedicated to understanding how the metabolism of individual wine yeast strains contributes to and may help improve the sensory properties of the finished product (Borneman et al., 2008; González-Sáiz et al., 2014). However, much remains to be learned in this regard, particularly in terms of the profile of the organic acids that are produced or metabolised by yeast strains during fermentation. Organic acids play a significant role in the perception of wine quality, since their presence directly impacts on the perceived and total acidity of wines (Cole \& Noble, 1997). Indeed, the most prominent and easily perceived sensory balance in wine is between acidity and sweetness. Complexity arises in this regard, however, as several different organic acids are found in wines, and each of these acids contributes differently to total wine acidity, and each also has specific and unique organoleptic properties (Table 1).

Tartaric, malic and citric acids are the most notable primary organic acids present in grapes and also contribute the largest proportion of titratable acidity to wine (Shiraishi et al., 2010). They are also known to contribute, directly or indirectly, to wine colour and stability (Boulton et al., 1996). In the case of wines with total acidity below desirable levels, acidification is often accomplished by tartaric acid addition, a practice that is commonly applied in warmer climates where grapes are frequently harvested with relatively low acidity levels and high sugar contents (Coulter et al., 2008; Santos et al., 2008).

In most cases, grape acids are unaffected by alcoholic fermentation, although some reports have indicated that malic acid in particular can be affected by the process. However, yeast releases a number of additional organic acids, resulting in changes in the final taste and an overall acidification of the wine (Volschenk et al., 2006). The three most prominent

*Corresponding author: E-mail address: Florian Bauer: fb2@sun.ac.za [Tel.: +2721 808 4346; Fax: +2721 80837711$]$

Other authors: BorediChidi: chidi@sun.ac.za; DebraRossouw:debra@sun.ac.za; Astrid Buica: abuica@sun.ac.za

Acknowledgements: We thank Stellenbosch University, for research facilities. Funding for this work was provided by Winetech, THRIP and the National Research Foundation (NRF, South Africa), through Grant SARChI UID 83471 and the RCA grant (91448) 
acids produced by yeast during fermentation are succinic, acetic and pyruvic acid, while the release of small amounts of fumaric and malic acid has also been reported.

Organic acid consumption and production by yeast during wine fermentation have been linked primarily to central carbon metabolism. Indeed, organic acids are intermediates or by-products of glycolysis or of the TCA cycle, but may also be derived from the glyoxylate pathway and from nitrogen metabolism (Kornberg \& Madsen, 1958; Popov et al., 2005). Under anaerobic conditions, the TCA cycle operates in a branched manner (Camarasa et al. 2003; $\mathrm{Tu}$ et al., 2005). Under these conditions, succinic acid is primarily produced as an end product of the reductive branch of the TCA cycle. Acetic acid is derived primarily from the oxidation of acetaldehyde by acetaldehyde dehydrogenases (Remize et al., 2000). Pyruvic acid, on the other hand, is produced as a product of glycolysis, in particular when downstream metabolic pathways, such as the production of ethanol from pyruvate, which otherwise would utilise pyruvic acid, are overwhelmed.

Factors that affect the production of some of these organic acids, in particular acetic acid, have been studied extensively (Usseglio-Tomasset, 1995; Bisson, 1999; Bely et al., 2005; Ferreira et al., 2006). Bely et al. (2005) noted a sharp increase in acetic acid levels in botrytised wines containing high levels of sugar. Similar findings for a high sugar medium were also reported by Ferreira et al. (2006). Other acids, such as succinic and pyruvic acid, have also been found to be influenced by temperature and $\mathrm{pH}$ variations in wine (Usseglio-Tomasset, 1995; Bisson, 1999). Torija et al. (2003) observed temperature effects on the growth of strains of $S$. cerevisiae in grape must and noted a significant increase in succinic and acetic acid as the fermentation temperature increased.

In addition, the influence of different yeast species and strains on organic acid production has been considered in a few earlier studies: Several authors have reported on the influence of Saccharomyces, as well as of some nonSaccharomyces yeasts, on selected organic acids present in wine (Charoenchai et al., 1998; Erasmus et al., 2004; Pigeau et al., 2007; Magyar et al., 2014). However, these studies were focusing on individual factors, such as yeast strain, $\mathrm{pH}$, sugar or temperature, and did not consider the complexity of the combination of different wine yeast genetic backgrounds combined with differences and changes in environmental parameters as well as in the composition of the must. The current study therefore investigated yeast strain-dependent differences in organic acid metabolism within the context of different fermentation conditions and environmental parameters.

The primary objective of this study was to investigate the impact of different commercial yeast strains in wine-like conditions under both anaerobic and aerobic conditions. For this purpose, the investigation compared the organic acid profiles produced by five widely used wine yeast strains, namely EC1118, DV10, VIN13, BM45 and 285, in two different synthetic musts and under different fermentation temperatures. These yeast strains have previously been shown to exhibit different characteristics in terms of fermentation kinetics, stress tolerance as well as the production of volatile
TABLE 1

Summary of the organic acids and their characteristics in wine.

\begin{tabular}{llll}
\hline $\begin{array}{l}\text { Organic } \\
\text { acids }\end{array}$ & $\begin{array}{l}\text { Level range } \\
(\mathbf{g} / \mathbf{L})\end{array}$ & Characteristics & References \\
\hline $\begin{array}{l}\text { Tartaric } \\
\text { acid }\end{array}$ & $4.5-15$ & Tart taste & $\begin{array}{l}\text { Ribéreau } \text { et al., } \\
2006\end{array}$ \\
$\begin{array}{l}\text { Malic } \\
\text { acid }\end{array}$ & $2-6.5$ & Sour taste & $\begin{array}{l}\text { Ribéreau } \text { et al., } \\
2000\end{array}$ \\
$\begin{array}{l}\text { Citric } \\
\text { acid }\end{array}$ & $0.5-1.0$ & Freshness & $\begin{array}{l}\text { Kalathenos } \text { et al., } \\
1995\end{array}$ \\
$\begin{array}{l}\text { Acetic } \\
\text { acid }\end{array}$ & $0.2-0.6$ & Vinegar sour aroma & Bely et al., 2005 \\
$\begin{array}{l}\text { Pyruvic } \\
\text { acid }\end{array}$ & $0.01-0.5$ & Slightly sour & Usseglio-Tomasset, \\
Succinic & $0.5-1.5$ & Salty bitter taste & Margalit, 1997 \\
acid & & & \\
\hline
\end{tabular}

TABLE 2

Industrial yeast strains' information and their fermentative characteristics as specified by supplier.

\begin{tabular}{|c|c|c|}
\hline Strain & $\begin{array}{l}\text { Commercial } \\
\text { supplier }\end{array}$ & Characteristics \\
\hline VIN13 & Anchor Yeast & $\begin{array}{l}\text { Short lag phase; ferments sugar fully } \\
\text { even at low temperature. Low nitrogen } \\
\text { requirements. }\end{array}$ \\
\hline EC1118 & Lallemand & $\begin{array}{l}\text { It ferments well at low temperatures and } \\
\text { flocculates well with very compact lees. } \\
\text { Fast fermenter and a killer yeast. Low } \\
\text { nitrogen requirements. }\end{array}$ \\
\hline BM45 & Lallemand & $\begin{array}{l}\text { BM45 is a relatively slow starter and is well } \\
\text { suited for long maceration programmes. It } \\
\text { has high nitrogen requirements. }\end{array}$ \\
\hline DV10 & Lallemand & $\begin{array}{l}\text { DV10 has strong fermentation kinetics } \\
\text { over a wide temperature range and } \\
\text { relatively low nitrogen demands. DV } 10 \\
\text { is famous for its ability to ferment under } \\
\text { stressful conditions of low } \mathrm{pH} \text {, high total } \\
\mathrm{SO}_{2} \text { and low temperature. }\end{array}$ \\
\hline 285 & Lallemand & $\begin{array}{l}\text { Ideal for aromatic white and rosé } \\
\text { wines with high alcohol potential, low } \\
\text { fermentation temperatures and low } \\
\text { nitrogen level requirements. }\end{array}$ \\
\hline
\end{tabular}

aromatic compounds (Rossouw et al., 2008; 2009). The two fermentation conditions were selected to reflect relatively extreme wine-like conditions; the first condition corresponds to what may be encountered in a cool climate white wine fermentation $(150 \mathrm{~g} / \mathrm{L}$ of sugar, a low $\mathrm{pH}$ of 3 , and a cold fermentation temperature of $15^{\circ} \mathrm{C}$ ), while the second more closely reflects a warmer climate red wine fermentation (250 $\mathrm{g} / \mathrm{L}$ of sugar, a $\mathrm{pH}$ of 4 and a fermentation temperature of $30^{\circ} \mathrm{C}$ ). The widely divergent and relatively extreme nature of these two conditions should allow for describing the broader organic acid production space of yeast and of strain-related acid variations in the broader fermentation context. 


\section{MATERIALS AND METHODS}

\section{Strains and culture conditions}

The commercial yeast strains, as well as some of their relevant characteristics as described by the manufacturers (Lallemand and Anchor), are listed in Table 2. Yeast cells were cultivated at $30^{\circ} \mathrm{C}$ in YPD synthetic media $(1 \%$ yeast extract; Biolab, South Africa), 2\% peptone (Fluka, Germany) and $2 \%$ dextrose (Sigma, Germany). Solid medium was supplemented with 2\% agar (Biolab, South Africa). YPD pre-culture medium was sterilised at $121^{\circ} \mathrm{C}$ for $15 \mathrm{~min}$, maintained at $4^{\circ} \mathrm{C}$ and renewed monthly. Yeast cultures were grown in $50 \mathrm{ml}$ shake-flasks on YPD at $30^{\circ} \mathrm{C}$ and at 250 $\mathrm{rpm}$. These cultures were harvested and washed with sterile distilled water, and the cells were inoculated at an $\mathrm{OD}_{600}$ of 0.1 (i.e. an initial cell density of approximately $10^{6} \mathrm{cfu} / \mathrm{ml}$ ).

\section{Fermentation medium}

Fermentation experiments were conducted in the defined synthetic must MS300, which resembles a natural must - as described previously (Bely et al., 1990). For the purposes of this study, the medium contained equimolar amounts of glucose and fructose at a total of either 150 or $250 \mathrm{~g} / \mathrm{L}$ (for the 'cool' and 'warm' climate setting respectively). Temperature and $\mathrm{pH}$ were set at 15 and $30^{\circ} \mathrm{C}$ and 3.0 and 4.0 respectively. The initial $\mathrm{pH}$ was adjusted with sodium hydroxide. Two sets of fermentations were carried out in $250 \mathrm{ml}$ Erlenmeyer flasks (containing $100 \mathrm{ml}$ of the medium) under aerobic and anaerobic conditions. Anaerobic fermentations were sealed with rubber stoppers with a $\mathrm{CO}_{2}$ opening, while under aerobic conditions, constant stirring at $200 \mathrm{rpm}$ was performed during the course of the fermentation. The fermentations were monitored for a period of 14 days. All batch fermentations were carried out in triplicate. The fermentation progress was monitored by daily weight loss measurements, and samples from the fermentation media were taken at days 2 (exponential phase), 5 (early stationary phase) and 14 (late stationary phase) for chemical analyses.

\section{Growth measurement}

Cell propagation (i.e. growth) was determined spectrophotometrically by measuring the optical density, at $600 \mathrm{~nm}$, of samples taken from re-suspended cell cultures during the fermentation period.

\section{Chemical analysis}

A capillary electrophoresis (CE) method adapted from Soga and Ross (1997) was used to analyse and quantify the organic acid contents in synthetic must (MS300). Culture supernatants were obtained and analysed for sugars, ethanol and glycerol by high performance liquid chromatography (HPLC) on an AMINEX HPX-87H ion exchange column at $55^{\circ} \mathrm{C}$ using $5 \mathrm{mM} \mathrm{H}_{2} \mathrm{SO}_{4}$ as the mobile phase at a flow rate of $0.5 \mathrm{ml} \cdot \mathrm{min}^{-1}$. Agilent RID and UV detectors were used for detection and quantification. Analyses were carried out using the HP Chemstation software package (Eyeghe-Bickong et al., 2012).

\section{Multivariate data analysis}

The trends within various sets of data were investigated by principal component analysis (PCA; Latentix 2.0, Brandon
Gray Internet Services, Inc.). The PCA data was transformed using the auto-scale function and the PCA models were calculated. Based on the experimental design, the samples represent the different fermentations (three independent replicates for each of the five strains) at different time points. The trends and variables considered are the result of changes in organic acid contents in the MS00 by wine yeast strains subjected to different environmental conditions $(\mathrm{pH}$, temperature, initial sugar levels and aeration).

\section{RESULTS AND DISCUSSION}

Fermentation kinetics of strains subjected to warm climate "red" wine and cool climate "white" wine fermentation conditions

Under all conditions, yeast growth and fermentation kinetics of the five strains followed similar trends, with some minor differences in the absolute values of certain parameters between strains. Fig. 1 shows similar rates of weight loss between anaerobic and aerobic red wine-like conditions. Under both conditions, the yeast reached stationary phase at roughly the same time, although a slight increase in optical density (hence total biomass) was observed under aerobic conditions. Similar patterns were also observed under white wine-like conditions (data not shown). This is not surprising; although $S$. cerevisiae is one of the few yeast species that grows well under anaerobic conditions, oxygen availability (particularly in the early stages of fermentation) supports mixed respiro-fermentative metabolism, leading to increased biomass production (Rigoulet et al., 2004).

Ethanol production, as well as total glucose and fructose utilisation of the five strains, was further analysed (Table 3). In all likelihood the high initial sugar content $(250 \mathrm{~g} / \mathrm{L})$ of the "red wine" setting and the low temperature and $\mathrm{pH}$ of the "white wine" setting were responsible for fermentations with residual sugars above $5 \mathrm{~g} / \mathrm{L}$ in some cases. Overall, VIN13 fermentations presented the lowest levels of residual sugars, while inoculation with BM45 generally resulted in the highest amounts under both red and white conditions (Table 3). As is usually observed with $S$. cerevisiae, fructose was the major contributing hexose to residual sugar levels, but conditions clearly affected the ratio between glucose and fructose. However, no general trends could be observed regarding strains and/or environmental conditions with regard to this parameter.

\section{The influence of yeast strain on grape-derived acids}

Organic acid analysis was carried out at three different time points for the "red" and "white" wine fermentations inoculated with the five different wine yeast strains. Concentrations of, and changes to, the major grape-derived acids, such as tartaric, malic and citric acid, were evaluated: In general, a slight decrease in the overall concentration of the grape acids was observed (Fig 2A and B). The concentration of all three grape acids diminished by approximately 10 to $20 \%$ of the initial amounts under both aerobic and anaerobic conditions. While there were no significant differences in grapederived acids between most of the strains under anaerobic conditions, DV10 fermentations resulted in significantly reduced levels of all three acids at the end of fermentation (Fig. 2A). Although precipitation is a main cause of tartaric 


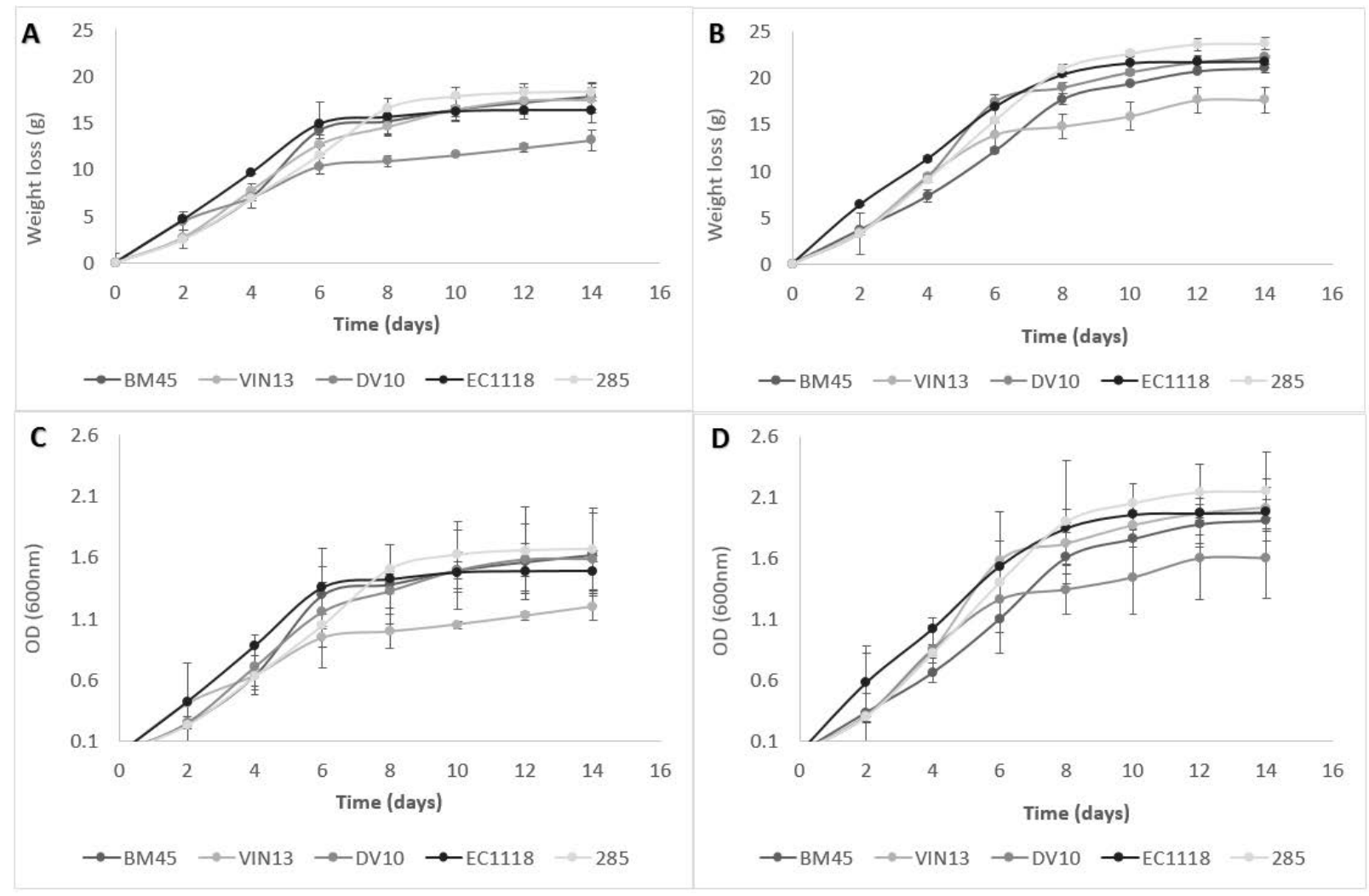

FIGURE 1

Fermentation kinetics of wine yeast under "red wine" settings. Anaerobic fermentation rates (frame A), aerobic fermentation rates (frame B), anaerobic growth rates (frame C) and aerobic growth rates (frame D). Results are the average of three biological repeats \pm standard deviation.

acid reduction in some young bottled wines, we did not observe any precipitate in any of the wines based on visual inspection. There also was no evidence that yeast strains of Saccharomyces can effectively transport or degrade tartaric acid, but it is possible that other, unknown bio-chemical transformations occurred in the DV10 fermentations to account for the lower overall grape-derived acid levels observed for this strain at the end of fermentation.

The impact of yeast strain on organic acid evolution under different winemaking conditions

In the light of the importance of end-point organic acid profiles, PCA analysis was performed using organic acid concentrations in the red and white wine conditions at the end of fermentation (Fig. 3). Only PCA plots generated for the anaerobic conditions are shown here, as this scenario is more relevant from a winemaking perspective and the aerobic PCAs did not contribute additional insights on strain-specific behaviour.

Replicates clustered well, indicative of good sample reproducibility. Samples were also clearly separated in strain-specific clusters, with some strains, such as EC1118 and VIN13, exhibiting similar organic acid profiles at the end of fermentation in the white wine-like conditions (Fig. 3A), while VIN13 and 285 were most similar in terms of their total organic acid profiles under the red wine-like conditions (Fig. 3B). BM45 was the most dissimilar to the other four strains in the fermentations in both the red and white wine settings.

\section{Succinic acid}

Succinic acid increased throughout fermentation for all strains and all environmental conditions, but significant differences were observed between strains in terms of the actual concentrations of succinic acid produced. As an example, Fig. 4 shows succinic acid concentrations at days 2, 5 and 14 for strain EC1118 in both the white (Fig. 4A) and red (Fig. 4B) wine settings. Similar succinic acid accumulation trends were also observed for other strains under similar conditions (data not shown). The increase in succinic acid levels during fermentation has been reported previously (Peynaud \& Blouin, 1996; Ribéreau-Gayon et al., 2006); however, there is little information on how different strains of yeast influence succinic acid accumulation in wine.

Strain genetic background showed a strong effect on succinic acid production: Under anaerobic red wine conditions, VIN13 produced higher succinic acid levels (followed by 285), while DV10 produced relatively lower succinic acid levels than the rest by the end of fermentation (Fig. 5A). Similar trends were also observed for these two strains in the white wine anaerobic setting (Fig. 5A) at this and other time points of fermentation (days 2 and 5; Table 4A and $4 \mathrm{~B}$ ). It is known that DV10 is more tolerant of low $\mathrm{pH}$ wines, and it is a preferred yeast for Champagne base wine. The ability of DV10 to reduce overall acidity therefore might be a specific adaptation for such conditions. The two other strains, BM45 and EC1118, showed intermediate levels of this acid (Fig. 5A). 
TABLE 3

Residual glucose/fructose levels and ethanol production of BM45, EC1118, VIN13, DV10 and 285 at the end of fermentation under white and red wine-like conditions. Values are average of three independent biological repeats \pm standard deviation.

\begin{tabular}{lllllll}
\hline & \multicolumn{2}{c}{ Residual glucose $(\mathrm{g} / \mathbf{L})$} & \multicolumn{2}{c}{ Residual fructose $(\mathbf{g} / \mathbf{L})$} & \multicolumn{2}{c}{ Ethanol (\%v/v) } \\
\hline Strains & $\begin{array}{l}\text { White wine } \\
\text { conditions }\end{array}$ & $\begin{array}{l}\text { Red wine } \\
\text { conditions }\end{array}$ & $\begin{array}{l}\text { White wine } \\
\text { conditions }\end{array}$ & $\begin{array}{l}\text { Red wine } \\
\text { conditions }\end{array}$ & $\begin{array}{l}\text { White wine } \\
\text { conditions }\end{array}$ & $\begin{array}{l}\text { Red wine } \\
\text { conditions }\end{array}$ \\
\hline EC1118 & $1.71 \pm 0.001$ & $1.51 \pm 0.173$ & $5.83 \pm 0.001$ & $3.76 \pm 0.05$ & $10.78 \pm 0.06$ & $11.19 \pm 0.002$ \\
DV10 & $2.12 \pm 0.163$ & $0.91 \pm 0.298$ & $6.39 \pm 0.075$ & $6.51 \pm 0.061$ & $10.95 \pm 0.007$ & $11.34 \pm 0.013$ \\
BM45 & $3.83 \pm 0.102$ & $4.49 \pm 0.129$ & $9.07 \pm 0.068$ & $16.11 \pm 0.13$ & $10.61 \pm 0.007$ & $10.39 \pm 0.006$ \\
VIN13 & $0.48 \pm 0.139$ & $0.64 \pm 0.110$ & $0.55 \pm 0.009$ & $0.66 \pm 0.102$ & $9.95 \pm 0.055$ & $11.41 \pm 0.003$ \\
285 & $0.90 \pm 0.128$ & $1.10 \pm 0.147$ & $3.25 \pm 0.098$ & $4.18 \pm 0.054$ & $10.25 \pm 0.041$ & $11.40 \pm 0.015$ \\
\hline
\end{tabular}
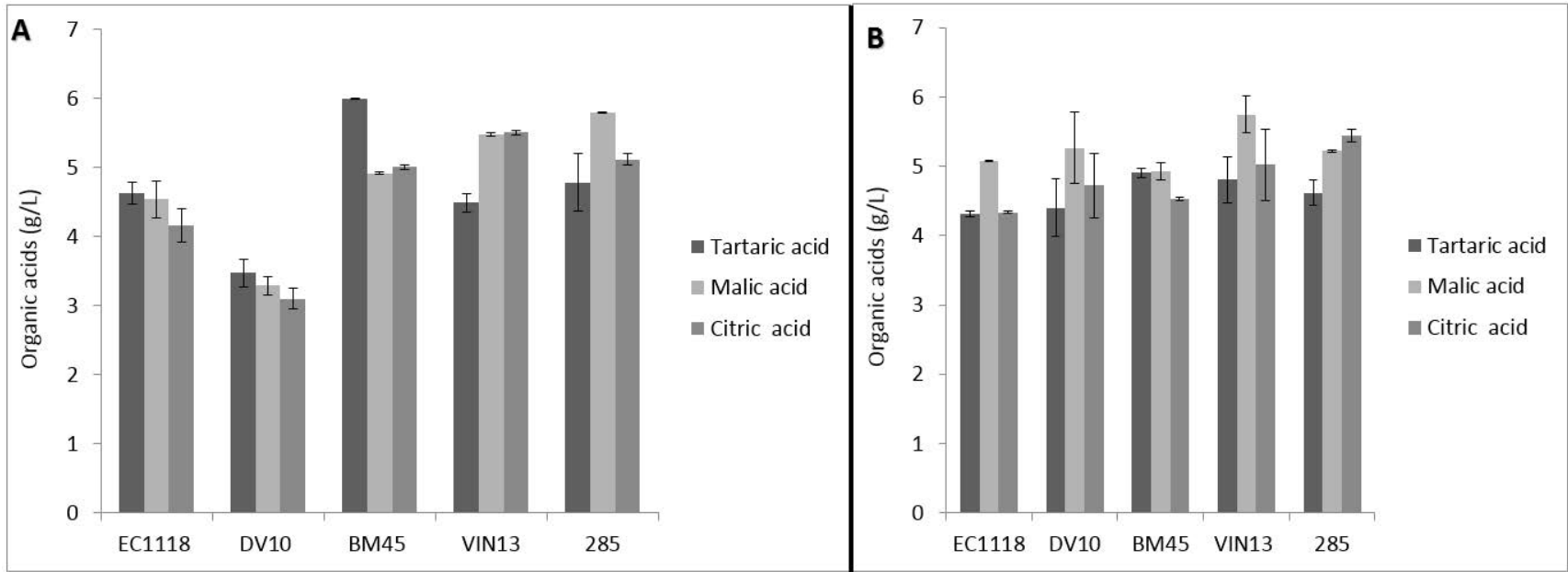

FIGURE 2

Grape-derived acid production by different yeast strains under the "red wine" setting at the end of fermentation under anaerobic (frame A) and aerobic (frame B) conditions. Results are the average of three biological repeats \pm standard deviation.

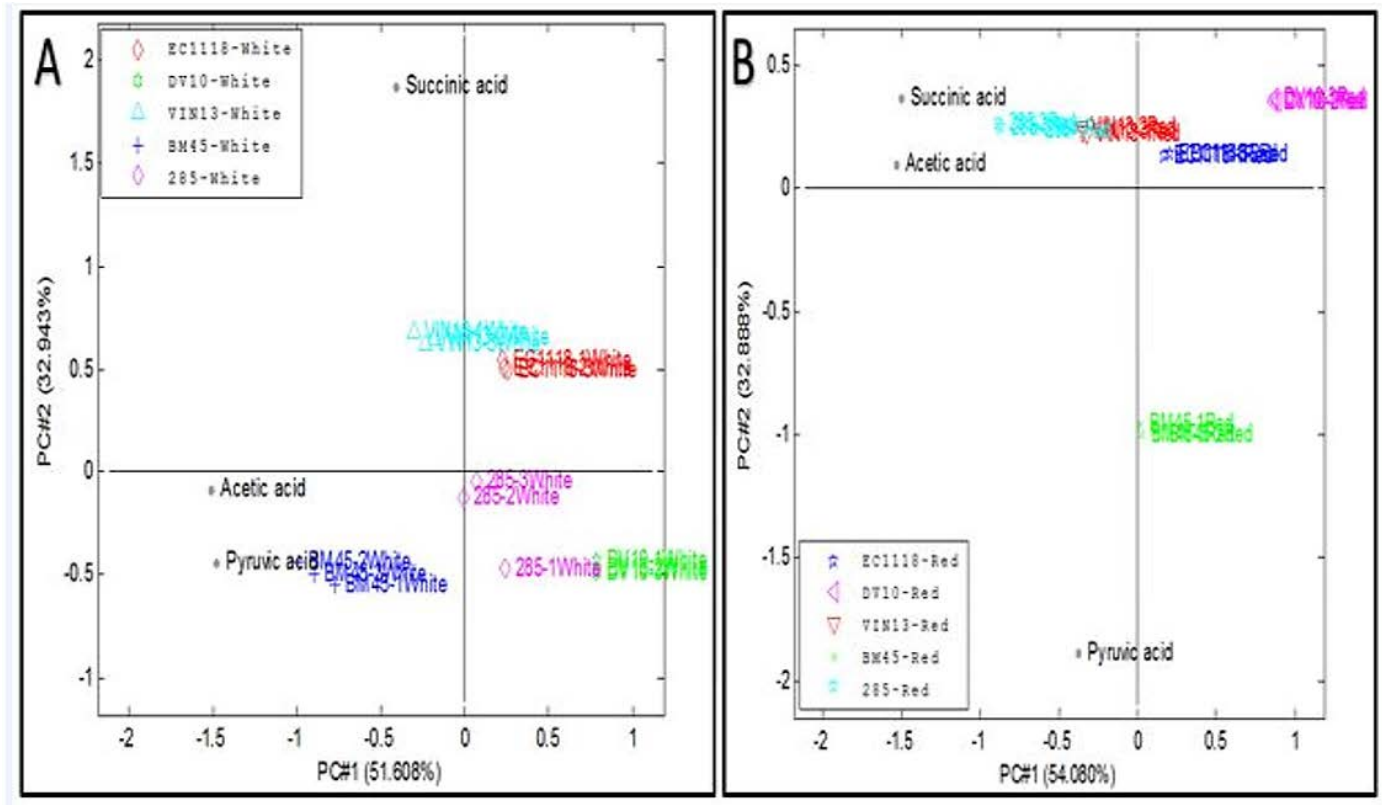

FIGURE 3

PCA bi-plot showing sample groupings for triplicate fermentations of strains DV10, BM45, VIN13, 285 and EC1118 at day 14 of fermentation. Fermentations were carried out under anaerobic white wine-like conditions $\left(150 \mathrm{~g} / \mathrm{L}, \mathrm{pH} 3\right.$ and $15^{\circ} \mathrm{C}$; frame $\left.\mathrm{A}\right)$ and red wine-like conditions $\left(250 \mathrm{~g} / \mathrm{L}, \mathrm{pH} 4\right.$ and $30^{\circ} \mathrm{C}$; frame $\left.\mathrm{B}\right)$. 
Succinic acid levels were significantly higher under aerobic conditions for all strains under both fermentation conditions (Fig. 4). This observation is in line with expectations, since it has been reported that organic acid levels in wine will generally be significantly augmented under aerobic conditions compared to anaerobic conditions (Wiebel et al., 2008). An increase in succinic acid concentrations has previously been linked to the shift in central carbon metabolism of yeast from fermentative to respiratory (Larsson et al., 1993; Coulter et al., 2004; Aceituno et al., 2012). Under aerobic conditions, VIN13 remained the highest producer of succinic acid under both the white and red wine conditions (Fig. 5B), while strain 285 was the lowest producer under these conditions. The levels of succinic acid produced by the other three strains for both fermentation settings under aerobic conditions were more or less similar at the end of fermentation (Fig. 5B).

It has previously been shown that increasing the addition of succinic acid by $0.1 \mathrm{~g} / \mathrm{L}$ in wines presents a detectable sensory impact to assessors (Baron \& Fiala, 2012). In the current study, succinic acid variations among strains was significantly higher than the $0.1 \mathrm{~g} / \mathrm{L}$ increments used by Baron and Fiala (2012) under both the red and white wine settings (Fig 5A and 5B). As a result, the strain-dependent differences observed here are likely to affect the sensory properties of wines in a notable manner.

\section{Acetic acid}

All strains behaved similarly with regard to acetic acid production over the time points considered. Fig. 6 shows a representative dataset for one of the strains, namely EC1118. Acetic acid levels in all fermentations increased rapidly at the beginning of fermentation. At the later time points, aerobic and anaerobic fermentations showed divergent patterns:
Under aerobic conditions, a continuous decrease was observed throughout fermentation in the case of the white wine setting $\left(150 \mathrm{~g} / \mathrm{L}, \mathrm{pH} 3,15^{\circ} \mathrm{C}\right)$, whereas a continuous increase in acetic acid was noted in the red wine setting $\left(250 \mathrm{~g} / \mathrm{L}, \mathrm{pH} 4,30^{\circ} \mathrm{C}\right)$ (Fig. 6B). In contrast, the levels of this acid remained more or less the same across all time points in both white and red anaerobic conditions (Fig. 6).

Strain genetic background had a strong effect on acetic acid production: Under anaerobic red wine conditions, strain 285 produced relatively higher acetic acid levels (up to $0.4 \mathrm{~g} / \mathrm{L}$ ) compared to other strains such as DV10 (as low as $0.136 \mathrm{~g} / \mathrm{L}$; Fig. 7B). Similar strain behaviour was also observed in the exponential phase (day 2; DV10 - 0.181 g/L and $285-0.460 \mathrm{~g} / \mathrm{L}$ ) and the early stationary phase (day 5 ; DV10 $-0.148 \mathrm{~g} / \mathrm{L}$ and $285-0.243 \mathrm{~g} / \mathrm{L}$ ), highlighting the strong impact of the selection of yeast strains on acetic acid production throughout fermentation (Table 4A and 4B). Acetic acid at high concentrations is undesirable because of the volatile nature and vinegary character of this organic acid (Remize et al., 2000). On the other hand, fermentations carried out in the white wine setting (under anaerobic conditions) showed no significant variations in acetic acid levels among strains, with the exception of strain DV10, which produced extremely low levels of acetic acid (Fig. 7A).

The impact of several yeast strains (N96, 71B, EC1118, V1116, VIN13 and VIN7) on acetic acid production in ice wines was previously explored through sensory evaluations (Erasmus et al., 2004). Variations in acetic acid concentration of between 0.1 and $0.8 \mathrm{~g} / \mathrm{L}$ were detected by the panel of evaluators. The differences in acetic acid levels between 285 $(0.5 \mathrm{~g} / \mathrm{L})$ and DV10 $(0.15 \mathrm{~g} / \mathrm{L})$ under anaerobic "red wine" fermentations will thus likely impart a significant sensorial impact on the wines produced.

Under aerobic conditions, acetic acid concentrations at

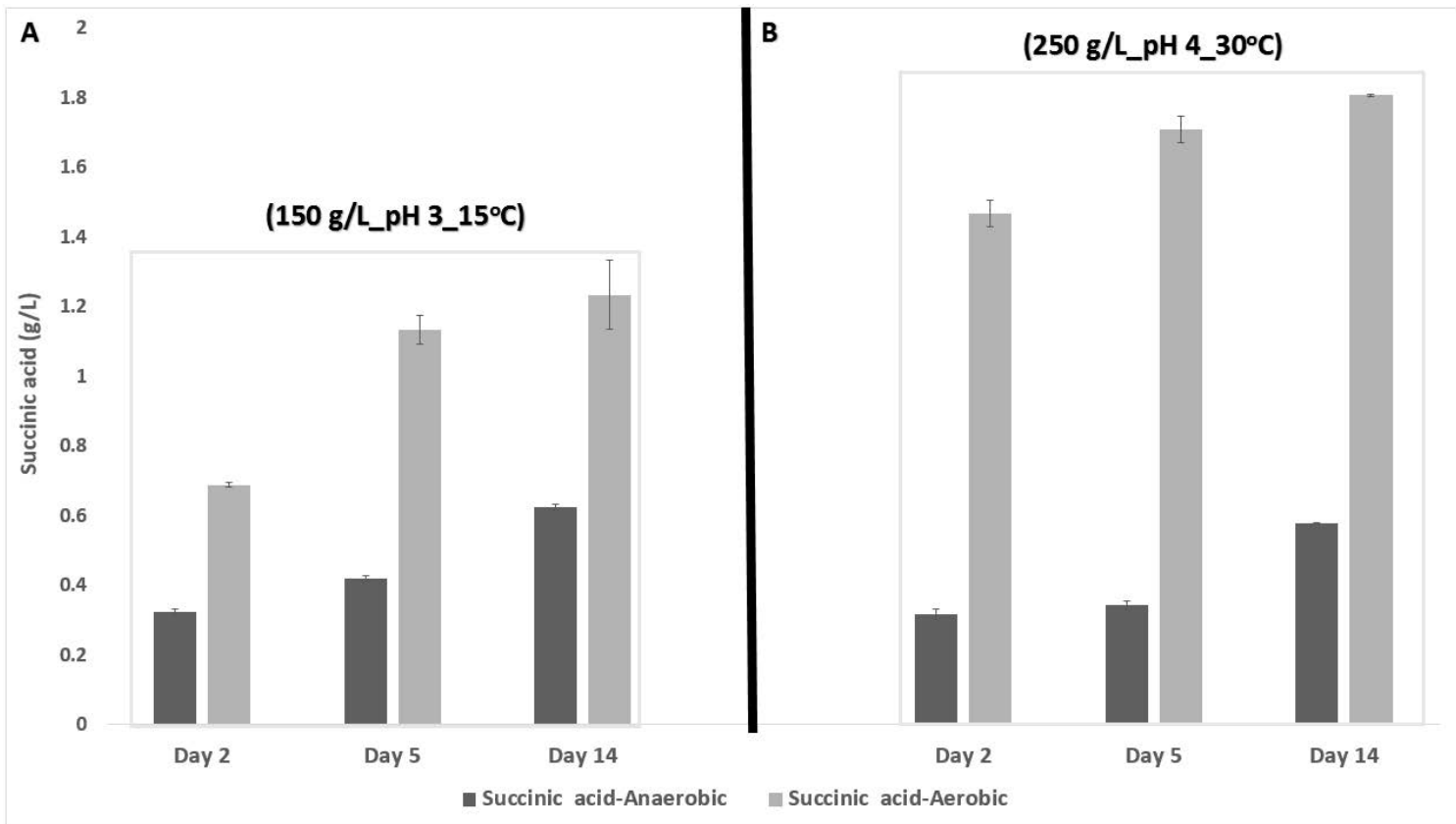

FIGURE 4

Succinic acid production by EC1118 at different fermentation stages (days 2, 5 and 14) under anaerobic and aerobic conditions. The graph shows succinic acid concentrations at three time points under white wine (A) and red wine (B) fermentation settings. Results are the average of three biological repeats \pm standard deviation. 
TABLE 4

The production of organic acid by five commercial wine yeasts and their response to white and red wine-like anaerobic and aerobic fermentation conditions at day 2 and 5 of fermentation.

\begin{tabular}{lllllll}
\hline A & \multicolumn{9}{c}{ Day 2 (Anaerobic) } \\
\cline { 2 - 7 } & \multicolumn{2}{c}{ Succinic acid (g/L) } & \multicolumn{2}{c}{ Pyruvic acid (g/L) } & \multicolumn{2}{c}{ Acetic acid (g/L) } \\
\cline { 2 - 7 } Strains & White & Red & White & Red & White & Red \\
\hline EC1118 & $0.322 \pm 0.008$ & $0.315 \pm 0.015$ & $0.543 \pm 0.059$ & $0.144 \pm 0.005$ & $0.184 \pm 0.005$ & $0.201 \pm 0.035$ \\
DV10 & $0.255 \pm 0.032$ & $0.218 \pm 0.010$ & $0.107 \pm 0.005$ & $0.143 \pm 0.037$ & $0.181 \pm 0.003$ & $0.142 \pm 0.003$ \\
BM45 & $0.355 \pm 0.02$ & $0.372 \pm 0.006$ & $0.143 \pm 0.011$ & $0.186 \pm 0.006$ & $0.219 \pm 0.006$ & $0.227 \pm 0.003$ \\
VIN13 & $0.308 \pm 0.002$ & $0.458 \pm 0.008$ & $0.204 \pm 0.005$ & $0.360 \pm 0.009$ & $0.271 \pm 0.038$ & $0.197 \pm 0.002$ \\
285 & $0.421 \pm 0.001$ & $0.313 \pm 0.012$ & ND & $0.195 \pm 0.032$ & $0.460 \pm 0.023$ & $0.299 \pm 0.004$
\end{tabular}

$\mathbf{B}$

Day 5 (Anaerobic)

\begin{tabular}{lllllll} 
& \multicolumn{2}{c}{ Succinic acid $(\mathbf{g} / \mathbf{L})$} & \multicolumn{2}{c}{ Pyruvic acid $(\mathrm{g} / \mathbf{L})$} & \multicolumn{2}{c}{ Acetic acid $(\mathrm{g} / \mathrm{L})$} \\
\cline { 2 - 7 } Strains & White & Red & White & Red & White & Red \\
\hline EC1118 & $0.418 \pm 0.009$ & $0.342 \pm 0.013$ & $0.175 \pm 0.007$ & $0.339 \pm 0.008$ & $0.222 \pm 0.003$ & $0.160 \pm 0.006$ \\
DV10 & $0.226 \pm 0.004$ & $0.198 \pm 0.010$ & $0.108 \pm 0.008$ & $0.090 \pm 0.008$ & $0.148 \pm 0.007$ & $0.134 \pm 0.002$ \\
BM45 & $0.296 \pm 0.007$ & $0.484 \pm 0.006$ & ND & $0.123 \pm 0.008$ & $0.229 \pm 0.005$ & $0.266 \pm 0.006$ \\
VIN13 & $0.575 \pm 0.006$ & $0.611 \pm 0.013$ & $0.110 \pm 0.006$ & $0.368 \pm 0.006$ & $0.250 \pm 0.003$ & $0.248 \pm 0.013$ \\
285 & $0.311 \pm 0.026$ & $0.540 \pm 0.015$ & ND & $0.453 \pm 0.125$ & $0.243 \pm 0.012$ & $0.429 \pm 0.065$
\end{tabular}

C

Day 2 (Aerobic)

\begin{tabular}{lllllll} 
& \multicolumn{2}{c}{ Succinic acid $(\mathrm{g} / \mathrm{L})$} & \multicolumn{2}{c}{ Pyruvic acid $(\mathrm{g} / \mathrm{L})$} & \multicolumn{2}{c}{ Acetic acid $(\mathrm{g} / \mathbf{L})$} \\
\cline { 2 - 7 } Strains & White & Red & White & Red & White & Red \\
\hline EC1118 & $0.688 \pm 0.007$ & $1.466 \pm 0.038$ & $0.583 \pm 0.035$ & $0.604 \pm 0.010$ & $0.523 \pm 0.264$ & $0.292 \pm 0.001$ \\
DV10 & $0.677 \pm 0.091$ & $1.407 \pm 0.011$ & $0.590 \pm 0.112$ & $0.565 \pm 0.013$ & $0.251 \pm 0.025$ & $0.272 \pm 0.029$ \\
BM45 & $0.739 \pm 0.048$ & $0.533 \pm 0.038$ & $0.251 \pm 0.010$ & $0.369 \pm 0.022$ & $0.216 \pm 0.010$ & $0.194 \pm 0.007$ \\
VIN13 & $1.386 \pm 0.066$ & $1.745 \pm 0.068$ & $0.265 \pm 0.026$ & $0.373 \pm 0.033$ & $0.129 \pm 0.006$ & $0.136 \pm 0.007$ \\
285 & $0.242 \pm 0.021$ & $1.319 \pm 0.008$ & $0.462 \pm 0.010$ & $0.739 \pm 0.009$ & $0.375 \pm 0.057$ & $0.395 \pm 0.072$
\end{tabular}

D

Day 5 (Aerobic)

\begin{tabular}{lllllll} 
& \multicolumn{2}{c}{ Succinic acid (g/L) } & \multicolumn{2}{c}{ Pyruvic acid (g/L) } & \multicolumn{2}{c}{ Acetic acid (g/L) } \\
\cline { 2 - 7 } Strains & White & Red & White & Red & White & Red \\
\hline EC1118 & $1.133 \pm 0.042$ & $1.709 \pm 0.038$ & $0.856 \pm 0.047$ & $0.505 \pm 0.052$ & $0.318 \pm 0.019$ & $0.319 \pm 0.013$ \\
DV10 & $0.855 \pm 0.018$ & $1.709 \pm 0.018$ & $0.656 \pm 0.039$ & $0.489 \pm 0.005$ & $0.223 \pm 0.003$ & $0.220 \pm 0.010$ \\
BM45 & $1.834 \pm 0.017$ & $1.566 \pm 0.023$ & $0.535 \pm 0.014$ & $0.524 \pm 0.009$ & $0.105 \pm 0.003$ & $0.225 \pm 0.006$ \\
VIN13 & $2.195 \pm 0.065$ & $3.816 \pm 0.034$ & $1.249 \pm 0.016$ & $0.556 \pm 0.039$ & $0.149 \pm 0.002$ & $0.384 \pm 0.031$ \\
285 & $1.215 \pm 0.057$ & $1.386 \pm 0.008$ & $1.169 \pm 0.010$ & $0.586 \pm 0.198$ & $0.456 \pm 0.058$ & $0.397 \pm 0.023$
\end{tabular}

Values are means of three repeats \pm standard deviation. $\mathrm{ND}$ - not detectable below $0.039 \mathrm{~g} / \mathrm{L}$

the end of fermentation were the highest (up to $0.49 \mathrm{~g} / \mathrm{L}$ ) in fermentations carried out with EC1118 in the red wine setting. For this treatment, the other four strains (including DV10) produced similar levels of acetic acid (Fig. 7B). The same trends were observed at days 2 and 5 (Table 4C and D). In the white wine aerobic setting, BM45 produced the lowest levels of acetic acid.

Our data supports the findings of previous work, which has shown remarkable variations in acetic acid levels among 20 Saccharomyces cerevisiae strains tested in wine (Romano et al., 2003). Our data, however, also highlights the important point that, while certain strains could generally be described as lower acetic acid producers, this phenotype can be modulated by the prevailing fermentation conditions.

Pyruvic acid

With regard to pyruvic acid production across time points (days 2, 5 and 14), most strains behaved similarly in terms of overall production trends for this acid. Fig. 8 shows a representative dataset for strain EC1118. Pyruvic acid was produced early during fermentation and then slowly re-absorbed/utilised in the white wine anaerobic 


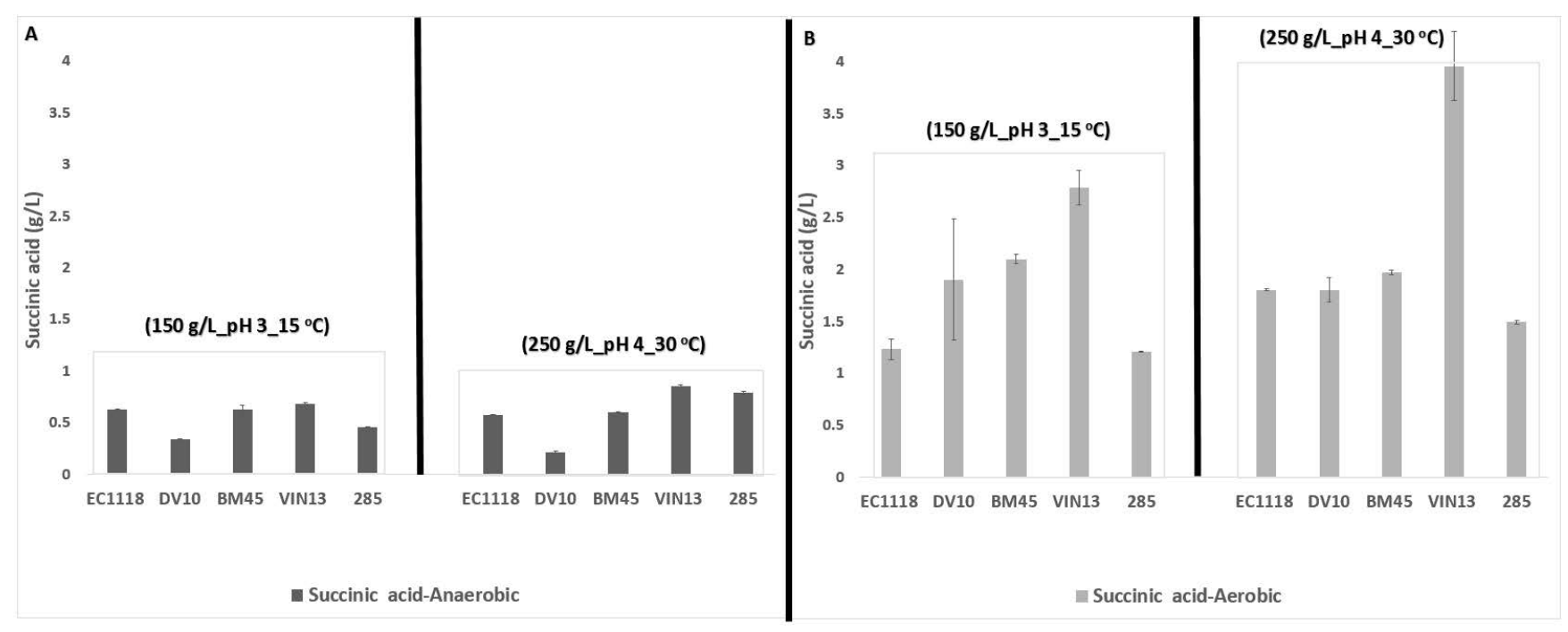

FIGURE 5

Succinic acid concentrations at the end of fermentation for five yeast strains in white wine and red wine fermentation settings under anaerobic (A) and aerobic fermentation conditions (B). Results are the average of three biological repeats \pm standard deviation.

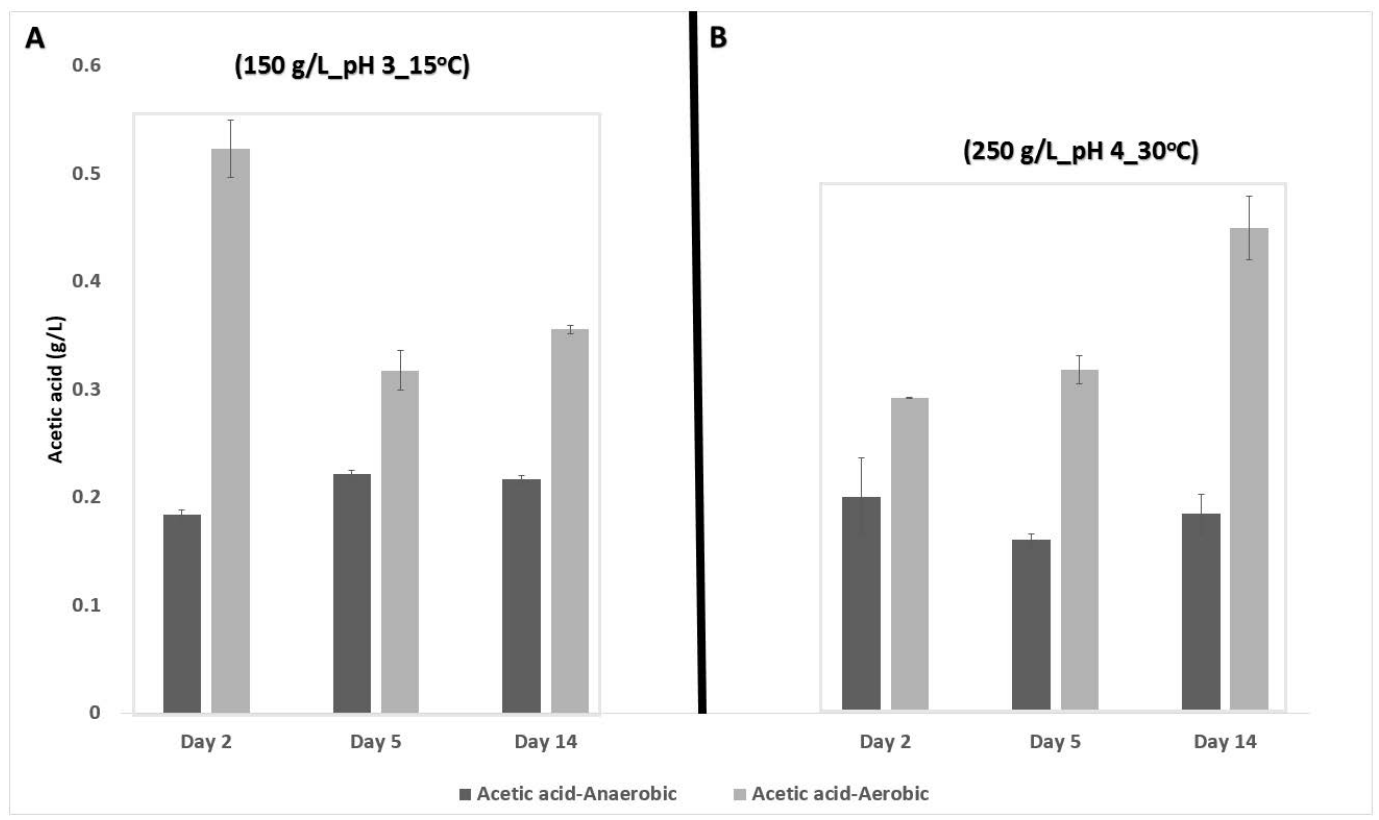

FIGURE 6

Acetic acid concentrations produced by EC1118 at different physiological and fermentation stages (day 2, 5 and 14) under anaerobic and aerobic conditions. The graph shows acetic acid variations over time under white wine (A) and red wine (B) fermentation conditions. Results are the average of three biological repeats \pm standard deviation.

fermentations (Fig. 8A). Similar observations have been reported elsewhere under winemaking conditions (Ribéreau et al., 2006). However the opposite trend was observed in the red wine anaerobic fermentation setting: Here, pyruvic acid levels initially were lower in the exponential phase but increased throughout fermentation (Fig. 8B). Under aerobic conditions the trends were very different: In the white wine setting, pyruvic acid levels initially were low for the exponential phase measurements, then increased towards the early stationary phase, before decreasing again (possibly due to reabsorption) by the late stationary phase (Fig. 8B).
However, in the red wine aerobic setting, pyruvic acid was produced early during fermentation and slowly reabsorbed as fermentation proceeded.

The impact of yeast strain identity on pyruvic acid production was evident under aerobic conditions at all the time points considered: On day 2 (the exponential phase), strains BM45 (0.339 g/L) and VIN13 (0.373 g/L) produced consistently low pyruvic acid levels in red wine settings compared to the other three strains (Table 4D). EC1118, 285 and DV10 produced the highest concentrations (0.604, 0.739 and $0.565 \mathrm{~g} / \mathrm{L}$ respectively) in these, as well as in the white 
wine fermentations $(0.583,0.462$ and $0.590 \mathrm{~g} / \mathrm{L})$ at this time point (Table 4C). While there were no significant differences among strains at day 5 in the 'red' wine fermentations, the VIN13 (1.249 g/L) and $285(1.169 \mathrm{~g} / \mathrm{L})$ fermentations showed higher concentrations of pyruvic acid for the 'white' wine setting at this time point (Table 4D).

Under aerobic conditions, strain VIN13 produced higher pyruvic acid levels (up to $0.7 \mathrm{~g} / \mathrm{L}$ ) by the end of fermentation, while strains DV10, BM45 and 285 produced the lowest levels in white wine conditions (Fig. 9A). These trends

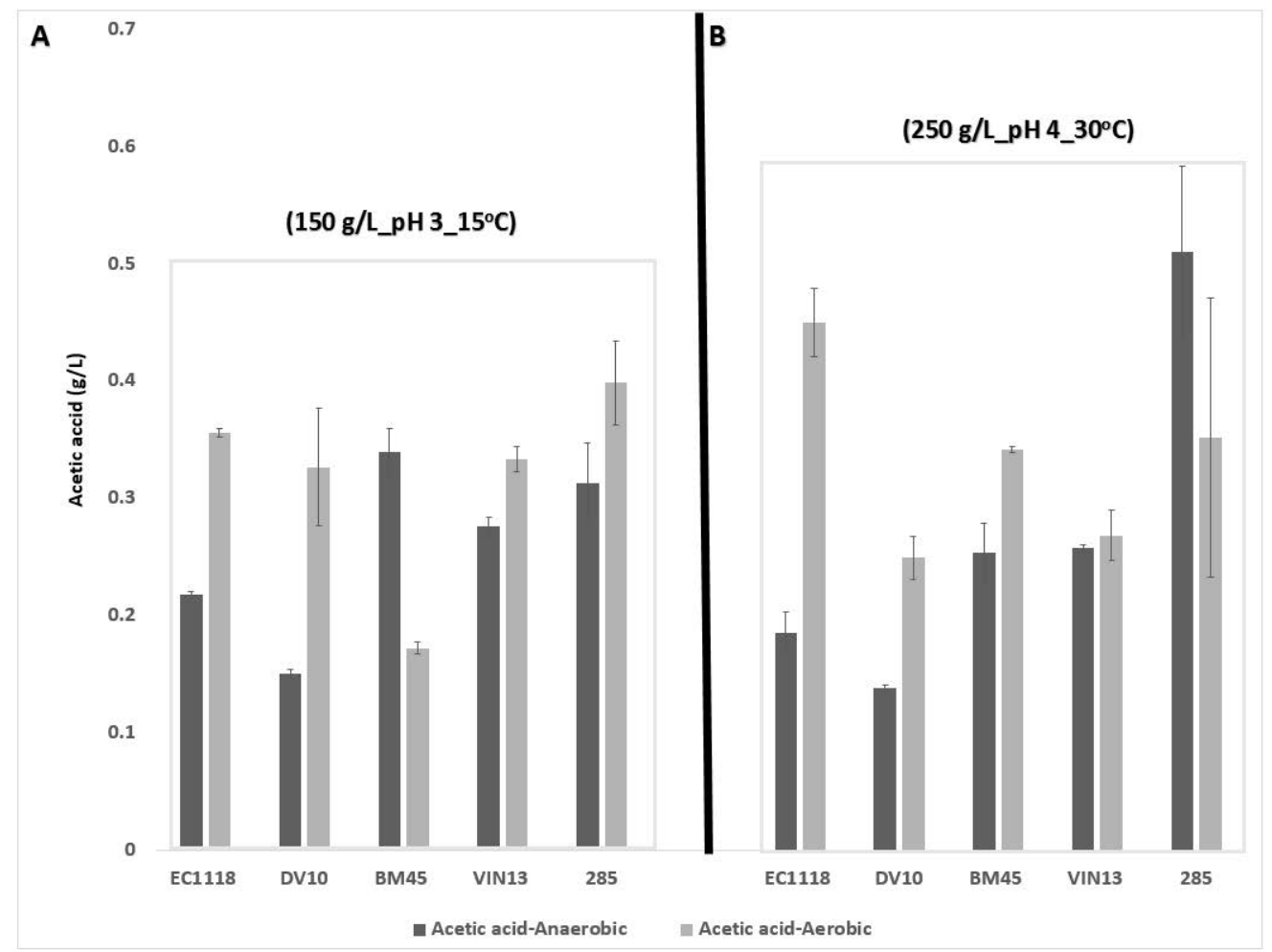

FIGURE 7

Acetic acid levels at the end of fermentation for five different yeast strains in white wine (A) and red wine (B) fermentation settings. Both aerobic and anaerobic conditions were analysed. Results are the average of three biological repeats \pm standard deviation.

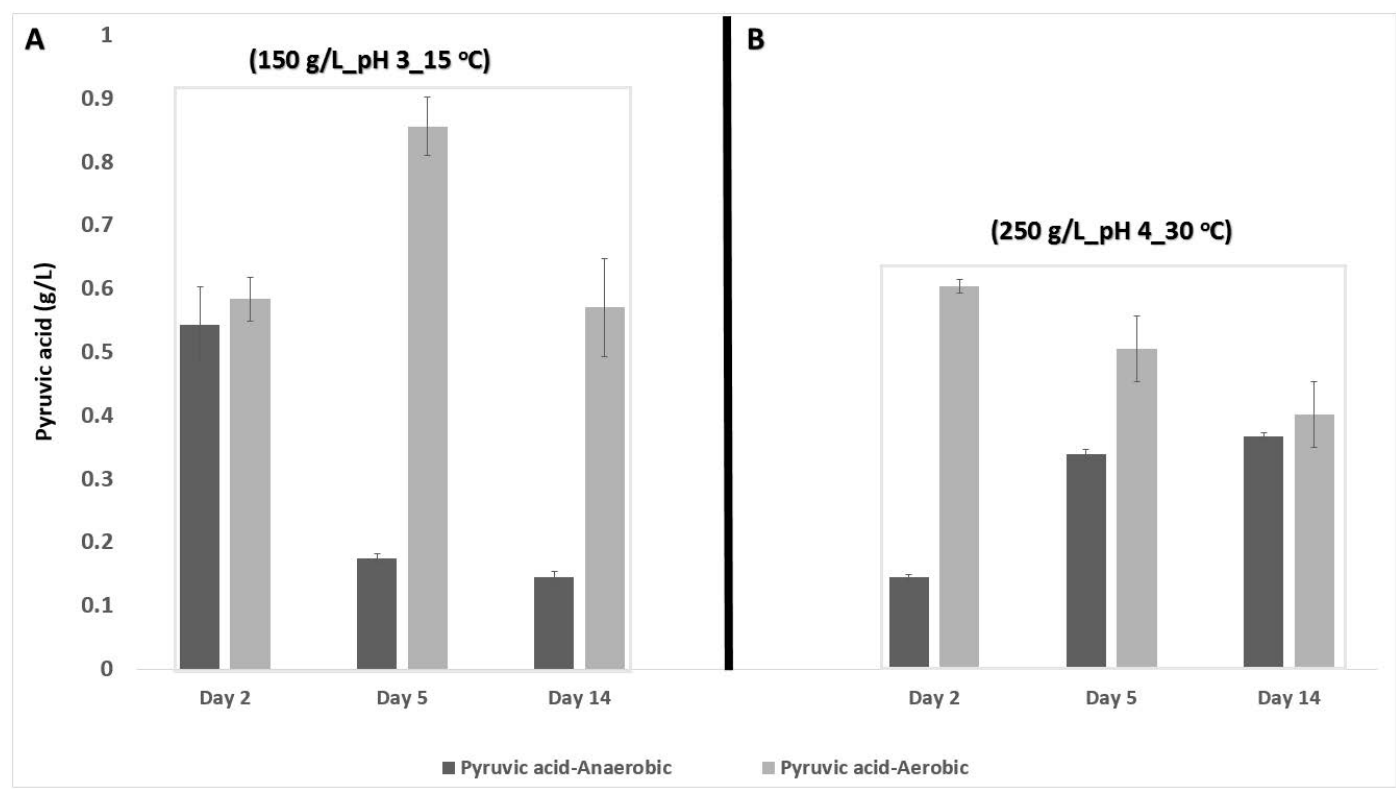

\section{FIGURE 8}

Pyruvic acid concentrations of EC1118-inoculated fermentations at different fermentation stages (day 2, 5 and 14) under anaerobic and aerobic conditions. The graph shows pyruvic acid variations over time in simulated white wine $(150 \mathrm{~g} / \mathrm{L}, \mathrm{pH}$ $\left.3,15^{\circ} \mathrm{C}\right)$ and red wine $\left(250 \mathrm{~g} / \mathrm{L}, \mathrm{pH} 4,30^{\circ} \mathrm{C}\right)$ fermentation conditions. Results are the average of three biological repeats \pm standard deviation. 


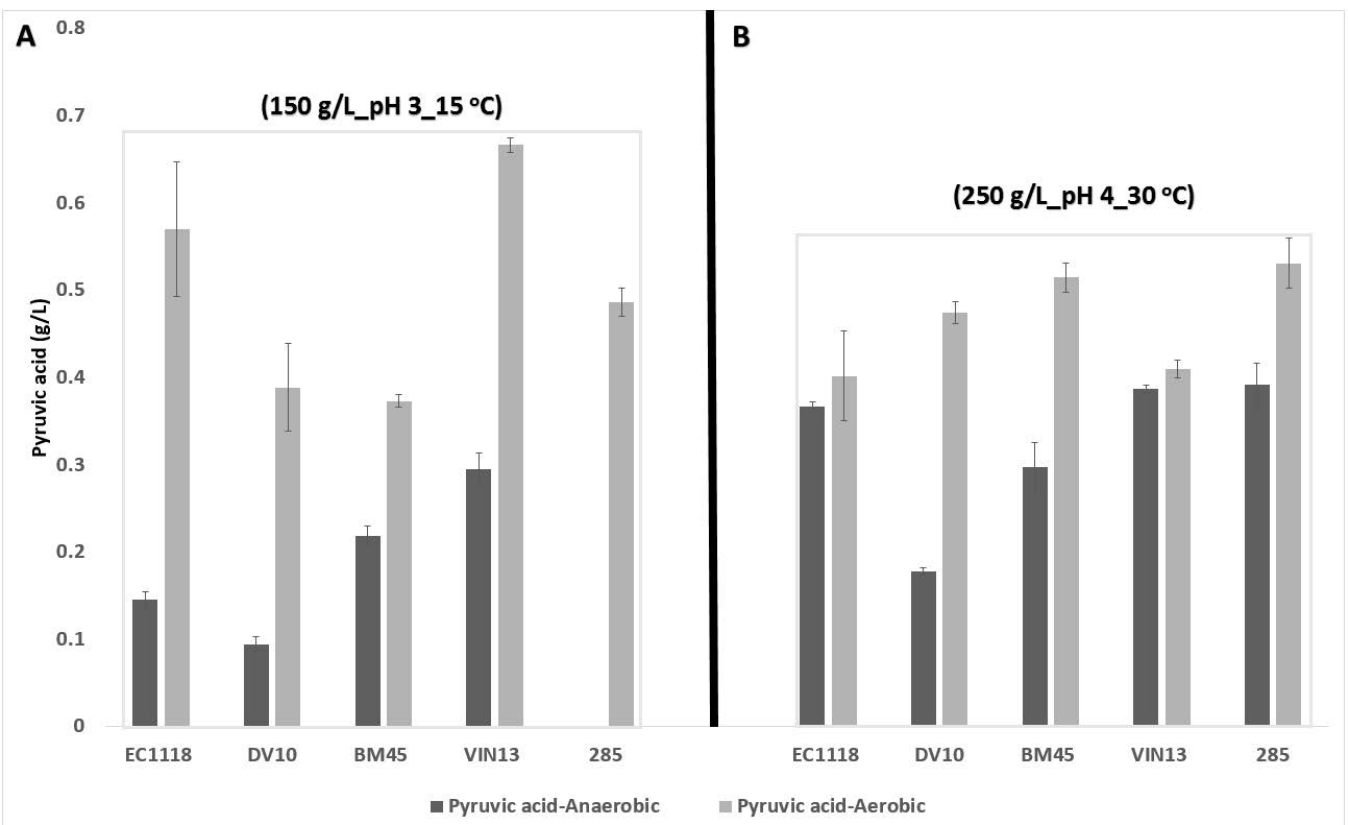

FIGURE 9

Pyruvic acid levels at the end of fermentation for five yeast strains in white wine (A) and red wine (B) fermentation setting conditions. Both aerobic and anaerobic fermentation conditions were analysed. Results are the average of three biological repeats \pm standard deviation.

are very different from those of the red wine conditions, where VIN13 was one of the lower pyruvic acid producers compared to all the other strains (Fig. 9B).

A completely different pattern was observed when the yeast strains were subjected to anaerobic fermentation conditions (Table 4). Fermentations at the exponential phase in the white wine conditions showed the highest pyruvic acid production/release by EC1118 $(0.543 \mathrm{~g} / \mathrm{L})$, while for strain 285 the levels of pyruvic acid were below the detection threshold (Table 4A). At this stage there were no significant strain-dependent differences in the red wine setting. However, by the early stationary phase there were significant differences in the red wine conditions, as fermentations conducted by EC1118, VIN13 and 285 showed significantly higher pyruvic acid concentrations $(0.339,0.368$ and $0.453 \mathrm{~g} / \mathrm{L}$, respectively) compared to the others (Fig. 9B). In contrast, pyruvic acid levels in the white wine fermentation were extremely low for all five strains (Table 4B).

By the end of anaerobic fermentation, the DV10 treatment showed relatively low pyruvic acid levels in both the white and red wine settings, while strain 285 resulted in undetectable levels of pyruvic acid in the white wine setting only (Fig. 9A). This highlights the impact of fermentation conditions in terms of changing (exacerbating, eliminating or completely reversing) inter-strain trends in organic acid production. Large variations in pyruvic acid production in wine (especially under anaerobic conditions) have been reported previously, and the predicted range of this acid falls within a wide range of 10 to $500 \mathrm{mg} / \mathrm{L}$ (Usseglio-Tomasset, 1995). The factors responsible for these large variations in pyruvic acid production have not received much scientific attention. Our data suggests a strong influence of (i) strain variability, (ii) stage of fermentation and (iii) fermentation conditions. Although the sensorial influences of pyruvic acid in wine have not been given much attention, our study reports large variations in pyruvic acid levels for the strains tested - an outcome that is likely to affect the sourness of the wines produced, as suggested by Usseglio-Tomasset, 1995.

\section{CONCLUSIONS}

While the overall impact of fermentation on total acidity is a relatively well-established parameter and is commonly monitored, not much data has been published on the impact of individual wine yeast strains on the specific concentrations of the different organic acids present in wine. This study explored inter-strain differences between five commercially available wine yeast strains in terms of acid production/release at different physiological stages of growth (different time points throughout fermentation) and under two very different, yet possible, winemaking conditions that could be encountered in industry. The strains displayed minor differences in their fermentation kinetics, but in many cases significant differences in organic acid production were observed. Only extracellular organic acids were measured (obtained from the fermentation medium). It should be noted that these acids may not necessarily represent the in vivo metabolic production of acids. Indeed, the yeast-derived organic acids are primarily intermediates of central metabolic pathways, and most are involved in several different metabolic reactions and may be produced from different precursors.

While many other known and unknown factors (apart from yeast and environmental factors) may significantly affect the organic acid levels of wines, the particular focus of the current study was the influence of strain identity on organic acid production. Our data highlight the fact that organic acid production characteristics of strains are not embedded phenotypes (i.e. consistent irrespective of conditions). 
Clearly, the acid evolution of a given strain, while displaying certain trends, is conditioned by the interplay of various physicochemical parameters. Differences between strains in our study were moderated, or strongly influenced, by changes to the prevailing fermentation conditions, including changes to the $\mathrm{pH}$, fermentation temperature, initial sugar concentration and aeration.

However, specific strain-dependent trends were evident in some instances: For example, VIN13 appeared to be a higher producer of succinic acid under the different conditions, while DV10 was a consistent low producer of succinic acid (irrespective of aerobic, anaerobic, 'red' or 'white' wine conditions). Strains BM45 and EC1118 were generally intermediate succinic acid producers under all conditions evaluated. Apart from lower production by DV10, acetic acid concentrations did not appear to vary significantly between fermentations conducted with the remaining four strains under anaerobic conditions. For aerobic conditions, EC1118 was the highest acetic acid producer under both the red and white wine conditions. Pyruvic acid concentrations were the most variable, and no pattern was evident in terms of a particular strain displaying generally lower or higher production levels across treatments. These variations in organic acid profiles among strains may well be explained by differences in their genetic background (e.g. differences in the expression, regulation and activity of enzymes involved in glycolysis, or the reductive and oxidative branches of the TCA cycle).

Overall, this study provides novel information that could be incorporated into practical guidelines for winemakers seeking to manage wine organic acid profiles through appropriate strain selection. Our results identify strains with different levels of production of specific organic acids for both the white and red wine fermentation settings. The current study will therefore assist winemakers to make informed decisions relating to strains that will improve the management of acidity and the organoleptic properties of their wines.

\section{LITERATURE CITED}

Aceituno, F.F., Orellana, M., Torres, J., Mendoza, S., Slater, A.W., Melo, F. \& Agosin, E., 2012. Oxygen response of the wine yeast Saccharomyces cerevisiae EC1118 grown under carbon-sufficient, nitrogen-limited enological conditions. Appl. Environ. Microbiol. 78, 8340-8352.

Baron, M. \& Fiala, J., 2012. Chasing after minerality, relationship to yeast nutritional stress and succinic acid production. Czech. J. Food. Sci. 30, 188193.

Bely, M., Masneuf-Pomarede, I. \& Dubourdieu, D., 2005. Influence of physiological state of inoculum on volatile acidity production by Saccharomyces cerevisiae during high sugar fermentation. J. Int. Sci. Vigne Vin 39, 191-197.

Bely, M., Sablayrolles, J.M. \& Barre, P., 1990. Automatic detection of assimilable nitrogen deficiencies during alcoholic fermentation in oenological conditions. J. Ferment. Bioeng. 70, 245-252.

Bisson, L., 1999. Stuck and sluggish fermentations. Am. J. Enol. Vitic. 50, 107-119.

Borneman, A.R., Forgan, A.H., Chambers, P.J. \& Pretorius, I.S., 2008. Unravelling the genetic blueprint of wine yeast. Aust. NZ Wine Ind. J. 23, 23-25.
Boulton, R.B., Singleton, V.L., Bisson, L.F. \& Kunkee, R.E., 1996. Principles and practices of winemaking. Chapman \& Hall, New York. pp. $146-150$.

Camarasa, C., Grivet, J.P. \& Dequin, S., 2003. Investigation by 13C-NMR and tricarboxylic acid (TCA) deletion mutant analysis of pathways for succinate formation in Saccharomyces cerevisiae during anaerobic fermentation. Microbiol. 149, 2669-2678.

Charoenchai, C., Fleet, G.H. \& Henschke, P.A., 1998. Effects of temperature, $\mathrm{pH}$ and sugar concentration on the growth rates and cell biomass of wine yeasts. Am. J. Enol. Vitic. 49, 283-288.

Cole, V.C. \& Noble, A.C., 1997. Flavour chemistry and assessment. In: Law, A.G.H. \& Piggott, J.R. (eds.). Fermented beverage production. Blackie Academic \& Professional, London. pp. 361 - 385.

Coulter, A.D., Henschke, P.A., Simos, C.A. \& Pretorius, I.S., 2008. When the heat is on, yeast fermentation runs out of puff. Aust. J. Grape. Wine Res. $23,26-30$.

Erasmus, D.J., Cliff, M. \& Van Vuuren, H.J.J., 2004. Impact of yeast strain on the production of acetic acid, glycerol, and the sensory attributes of icewine. Am. J. Enol. Vitic. 55, 371-378.

Eyeghe-Bickong, H.A., Alexandersson, E.O., Gouws, L.M., Young, P.R. \& Vivier, M.A., 2012. Optimisation of an HPLC method for the simultaneous quantification of the major sugars and organic acids in grapevine berries. $\mathrm{J}$. Chrom. 885, 43-49.

Ferreira, J., Du Toit, M. \& Du Toit, W.J., 2006. The effects of copper and high sugar concentrations on growth, fermentation efficiency and volatile acidity production of different commercial wine yeast strains. Aust. J. Grape. Wine Res. 12, 50-56.

González-Sáiz, J.M., Esteban-Díez, I., Rodríguez-Tecedor, S., Pérez-delNotario, N., Arenzana-Rámila, I. \& Pizarro, C., 2014. Modulation of the phenolic composition and colour of red wines subjected to accelerated ageing by controlling process variables. Food Chem. 165, 271-281.

Kalathenos, P., Sutherland, J.P. \& Roberts, T.A., 1995. Resistance of some wine spoilage yeasts to combination of ethanol and acids present in wine J. Appl. Bacteriol. 78, 245-250.

Kornberg, H.L. \& Madsen, N.B., 1958. The metabolism of $\mathrm{C}_{2}$ compounds in micro-organisms. Synthesis of malate from acetate via the glyoxylate cycle. Biochem. J. 68, 549-557.

Larsson, C., Vonstockar, U., Marison, I. \& Gustafsson, L., 1993. Growth and metabolism of Saccharomyces cerevisiae in chemostat cultures under carbon-limiting, nitrogen-limiting, or carbon-limiting and nitrogen-limiting conditions. J. Bacteriol. 175, 4809-4816.

Magyar, I., Sardy, D.N., Lesko, A., Pomazi, A. \& Kallay, M., 2014. Anaerobic organic acid metabolism of Candida zemplinina in comparison with Saccharomyces wine yeasts. Int. J. Food Microbiol. 178, 1-6.

Margalit, Y., 1997. Must and wine composition - Concepts in wine chemistry. J. Crum (ed.). Wine Appreciation Guild Ltd., San Francisco, USA. pp. $76-82$.

Peynaud, E. \& Blouin, J., 1996. The taste of wine: The art and science of wine appreciation. John Wiley \& Sons, New York.

Pigeau, G.M., Bozza, E., Kaiser, K. \& Inglis, D.L., 2007. Concentration effect of Riesling ice-wine juice on yeast performance and wine acidity. J. Appl. Microbiol. 103, 1691-1698.

Popov, E.A., Moskalev, E.A., Shevchenko, M.U. \& Eprintsev, A.T., 2005. Comparative analysis of glyoxylate Cycle Key Enzyme Isocitrate lyase from organisms of different systematic groups. J. Evol. Biochem. Phys. 41, 631-639. 
Remize, F, Andrieu, E. \& Dequin, S., 2000. Engineering of the pyruvate dehydrogenase bypass in Saccharomyces cerevisiae: Role of the cytosolic $\mathrm{Mg}(2+)$ and mitochondrial $\mathrm{K}(+)$ acetaldehyde dehydrogenases Ald $6 p$ and Ald $4 p$ in acetate formation during alcoholic fermentation. Appl. Environ. Microbiol. 66, 3151-3159.

Ribéreau-Gayon, P., Glories, Y., Maujean, A. \& Dubourdieu, D., 2000. Handbook of enology. 2: The chemistry of wine stabilization and treatments, John Wiley \& Sons, Ltd, Chichester, UK

Ribéreau-Gayon, P., Glories, Y., Maujean, A. \& Dubourdieu, D., 2006 $\left(2^{\text {nd }} \mathrm{ed}\right)$. Handbook of enology - The chemistry of wine: Stabilization and treatments. John Wiley \& Sons Ltd., Chichester, UK.

Rigoulet, M., Aguilaniu, H., Averet, N., Bunoust, O., Camougrand, N., Grandier-Vazeille, X., Larsson, C., Pahlman, I.L., Manon, S. \& Gustafsson, L., 2004. Organization and regulation of the cytosolic NADH metabolism in the yeast Saccharomyces cerevisiae. Mol. Cell Biochem. 256/257, 73-81.

Romano, P., Fiore, C., Paraggio, M., Caruso, M. \& Capece, A., 2003. Function of yeast species and strains in wine flavour. Int. J. Food. Microbiol. $86,169-180$

Rossouw, D., Naes, T. \& Bauer, F.F., 2008. Linking gene regulation \& the exo-metabolome: A comparative transcriptomics approach to identify genes that impact on the production of volatile aroma compounds in yeast. BMC Genomics 9, 530-548.

Rossouw, D., Olivares-Hernandes, R., Nielsen, J. \& Bauer, F.F., 2009. Comparative transcriptomic approach to investigate differences in wine yeast physiology and metabolism during fermentation. Appl. Environ. Microbiol. 75, 6600-6612.
Santos, J., Sousa, M.J., Cardoso, H., Inacio, J., Silva, S., Spencer-Martins, I. $\&$ Leao, C., 2008. Ethanol tolerance of sugar transport and the rectification of stuck wine fermentations. Microbiol. 154, 422-430.

Shiraishi, M., Fujishima, H. \& Chijiwa, H., 2010. Evaluation of table grape genetic resources for sugar, organic acid and amino acid composition of berries. Euphytica 174, 1-13.

Soga, T. \& Ross, G.A., 1997. Capillary electrophoretic determination of inorganic and organic anions using 2,6-pyridinedicarboxylic acid: Effect of electrolyte's complexing ability. J. Chromatogr. 767, 223-230.

Torija, M.J., Beltran, G., Novo, M., Poblet, M., Guillamon, J.M., Mas, A \& Rozes, N., 2003. Effects of fermentation temperature and Saccharomyces species on the cell fatty acid composition and presence of volatile compounds in wine. Int. J. Food. Microbiol. 85, 127-136.

Tu, B.P., Kudlicki, A., Rowicka, M. \& McKnight, S.L., 2005. Logic of the yeast metabolic cycle: Temporal compartmentalization of cellular processes. Science 310, 1152-1158.

Usseglio-Tomasset, L., 1995 (4 ${ }^{\text {th }}$ ed). Chimica Enologica. AEB, Brescia.

Volschenk, H., Van Vuuren H.J.J. \& Viljoen-Bloom, M., 2006. Malic acid in wine: Origin, function and metabolism during vinification. S. Afr. J. Enol. Vitic. 27, 2-18.

Wiebel, M.G., Rintala, E., Tamminen, A., Simolin, H., Salusjarvi, L., Toivari, M., Kokkonen, J.T., Kiuru, J., Ketola, R.A., Jouhten, P., Huuskonen, A., Maaheimo, H., Ruohonen, L. \& Penttila, M., 2008. Central carbon metabolism of Saccharomyces cerevisiae in anaerobic, oxygen-limited and fully aerobic steady-state conditions and following a shift to anaerobic conditions. FEMS Yeast Res. 8, 140-154. 